\title{
Efficacy and safety of methotrexate in articular and cutaneous manifestations of systemic lupus erythematosus
}

\author{
Md. Nazrul ISLAM, ${ }^{1}$ Mohsin HOSSAIN, ${ }^{2}$ Syed A. HAQ, ${ }^{1}$ Mohammad N. ALAM, ${ }^{3}$ \\ Peter M. TEN KLOOSTER ${ }^{4}$ and Johannes J. RASKER ${ }^{4}$ \\ ${ }^{1}$ Rheumatology Wing, Department of Medicine, Bangabandhu Sheikh Mujib Medical University (BSMMU), ${ }^{2}$ National Institute of \\ Cardiovascular Diseases (NICVD), College Gate, Shyamoli, ${ }^{3}$ Samorita Hospital, Panthopath, Dhaka, Bangladesh; and \\ ${ }^{4}$ IBR Research Institute for Social Sciences and Technology, Faculty of Behavioral Sciences, University of Twente, Enschede, \\ the Netherlands
}

\begin{abstract}
Aim: A prospective open-label study comparing the efficacy and safety of methotrexate (MTX) and chloroquine (CQ) in articular and cutaneous manifestations of systemic lupus erythematosus (SLE).

Methods: Consecutive SLE patients were randomly assigned to either $10 \mathrm{mg}$ MTX weekly or $150 \mathrm{mg}$ CQ daily during 24 weeks. Outcome measures were: numbers of swollen and tender joints, duration of morning stiffness, visual analog scale (VAS) for articular pain, physician global assessment index, patient global assessment index, SLE Disease Activity Index (SLEDAI), disappearance of skin rash and erythrocyte sedimentation rate (ESR).

Results: Forty-one patients consented to participate, 15 were allocated in the MTX group and 26 in the CQ group. Two patients on MTX dropped out due to side-effects and two in the CQ group, one due to side-effects and one due to inefficacy. Baseline demographic, clinical and laboratory parameters of the two groups were nearly identical. In both groups the clinical and laboratory parameters improved significantly over 24 weeks, except the ESR in the MTX group. The results of the outcome measures at the end of the trial did not differ significantly between the two groups, except morning stiffness $(P<0.05$ in favor of the MTX group) and ESR $(P<0.01$ in favor of the CQ group). Rise of serum alanine aminotransferase was observed in two cases in the MTX group and in none in the CQ group.

Conclusion: Low-dose MTX appears to be as effective as CQ in patients with articular and cutaneous manifestations of SLE, having an acceptable toxicity profile. Results of this prospective study need to be confirmed in a larger study.
\end{abstract}

Key words: articular, chloroquine, cutaneous, methotrexate, SLE.

\section{INTRODUCTION}

Arthralgia and arthritis occur in approximately 90\% and skin and mucous membranes are involved in

Correspondence: Dr Md. Nazrul Islam, Associate Professor of Rheumatology, Rheumatology Wing, Department of Medicine, Bangabandhu Sheikh Mujib Medical University (BSMMU), Dhaka, Bangladesh.

Email: islam1nazrul@gmail.com
$80 \%$ of cases of systemic lupus erythematosus (SLE). ${ }^{1}$ Conventionally, antimalarials are used to control these articular and mucocutaneous manifestations in nonorgan threatening SLE. ${ }^{2}$ In a recent review of 95 articles on antimalarial treatment in SLE, high levels of evidence were found that both hydroxychloroquine (HCQ) and chloroquine (CQ) prevent lupus flares and increase long-term survival of patients with SLE; moderate evidence was found of protection against irreversible organ damage, thrombosis and bone mass 
loss. ${ }^{3}$ Toxicity related to antimalarials is infrequent, mild and usually reversible, ${ }^{3}$ with HCQ having a safer profile than $\mathrm{CQ}$, although comparative data come only from one observational study. ${ }^{4}$

In a retrospective study assessing the reasons for discontinuation of antimalarial drugs in SLE patients, $42 \%$ discontinued HCQ due to disease remission, $8 \%$ due to inefficacy and 29\% stopped because of adverse effects, particularly severe anorexia, nausea, headache dizziness, deafness, visual disturbance and myopathy. ${ }^{5}$ In a substantial proportion of cases, antimalarials induce and maintain only partial remission, necessitating addition of low to high doses of corticosteroids and sometimes cytotoxic drugs like azathioprine or cyclophosphamide, and antimalarials are especially inadequate in managing severe lupus, especially lupus nephritis. ${ }^{6}$

The high efficacy/toxicity trade-off and high longterm drug survival rates of methotrexate (MTX) have been documented in rheumatoid arthritis patients in several clinical trails ${ }^{7,8}$ and meta-analyses. ${ }^{9}$ Despite existence of some evidence as early as $1965,{ }^{10}$ the interest in the effects of MTX in SLE has grown only in recent years. In 1965, Miescher and Riethmüller ${ }^{10}$ used MTX at a dose of $50 \mathrm{mg} /$ week intravenously in 10 SLE patients with arthralgia, skin rash and vascular purpura. They noted a rapid response: the manifestations of SLE diminished within 1 or 2 weeks. Subsequently, MTX was proven to be effective in controlling articular and cutaneous manifestations of SLE in several clinical trials. ${ }^{11-21} \mathrm{~A}$ few of these trials were retrospective. $^{14,22,23}$ Other trials were uncontrolled and included either steroid-resistant patients ${ }^{13,15,20,21}$ or patients dependent on high doses of steroids. ${ }^{14,16-18}$ To our knowledge only two prospective randomized placebo-controlled trials on the effect of MTX in SLE have been published. The first by Carneiro and Sato ${ }^{24}$ reported the efficacy of 15-20 mg MTX in 41 patients controlling cutaneous and articular activity of SLE and corticosteroid dose reduction. Side-effects were frequent (gastrointestinal complaints and hepatic enzyme elevations) but only two out of 18 receiving MTX had to stop due to toxicity. A recent trial ${ }^{25}$ showed in a 12-month study a steroid-sparing effect of MTX 7.5 increasing to $20 \mathrm{mg}$ per week plus folic acid in 86 randomized patients with moderately active rather than severe lupus. To our knowledge the efficacy of MTX in non-severe SLE has been reported in only two doubleblind placebo-controlled trials. ${ }^{21,22}$ Considering the lack of tolerability or efficacy of antimalarials in subsets of patients and the long-term efficacy of MTX in steroid-resistant SLE and its relative safety, despite sometimes considerable side effects, ${ }^{24,25}$ it has become imperative to investigate its status as an alternative for antimalarials in non-organ-threatening articular and cutaneous SLE.

The present study was undertaken to compare the efficacy and toxicity of MTX with those of CQ in muco-cutaneous and articular SLE. The rationale is that in some cases antimalarials have insufficient effect and side-effects and a second affordable effective drug is necessary in developing countries such as Bangladesh. In this study CQ $150 \mathrm{mg}$ base tablet daily was chosen as it is the only antimalarial drug available for SLE in Bangladesh due to its low price.

We chose to keep a fixed weekly dose of $10 \mathrm{mg}$ MTX for the whole duration of the study, in order to assess the outcome at a fixed and low dose. The weight of most of the patients was in the range of 35$45 \mathrm{~kg}$, so the dosage per $\mathrm{kg}$ is comparable with that of higher dosages as used in Western countries, where people tend to have higher weight. We decided to study the efficacy at a stable and low MTX dose as many of the patients in daily Bangladeshi practice are using medical treatment without regular clinical follow-ups, due to often long distances to the hospitals and lack of funds to do blood tests. This means that changing dosages, in these often illiterate patients, would be difficult to control. Obviously, during our study all participating patients came for follow-up and laboratory tests at the allocated times.

\section{MATERIALS AND METHODS}

This prospective open-label randomized clinical trial was conducted at the lupus clinic of a tertiary care center in Dhaka, the capital of Bangladesh. The study period was June 2001 to November 2002 and included 6-month follow-up. Patients fulfilling American College of Rheumatology (ACR) criteria of SLE and suffering from arthralgia, or arthritis and active skin lesions, were selected for this study. A total of five patients refused to participate after explanation. Exclusion criteria were: involvement of any other systems, pregnancy, lactation, any form of eye problems, history of taking antimalarials within the last 4 months or corticosteroids equivalent to $>20 \mathrm{mg}$ of prednisolone per day, raised serum alanine aminotransferase (ALT), and raised serum creatinine.

All patients gave verbal consent. No written consent was attempted because participants were mostly illiterate. After obtaining informed verbal consent, the 
subjects were evaluated clinically and the following laboratory tests were done: routine urinalysis, complete blood counts (CBC), erythrocyte sedimentation rate (ESR), antinuclear antibodies (ANA), anti-doublestranded DNA (anti-dsDNA), serum ALT and creatinine. Serology-like anti-Sjögren syndrome A and B and antiphospholipid antibodies were not done due to financial constraints.

The patients were randomly allocated to either MTX or CQ groups. Randomization was performed following a random number table without considering their presentation. We followed the vertical series of odd and even numbers.

Methotrexate was given at a dose of $10 \mathrm{mg} /$ week and CQ $150 \mathrm{mg}$ per day to the respective groups throughout the study period of 24 weeks. The patients were allowed to continue corticosteroids in a fixed dose that they were taking for at least 2 months before the start of the study and at doses not exceeding $10 \mathrm{mg} /$ day. Increasing the dose was not permitted, also not in any other route like intramuscular, intravenous or intra-articular.

\section{Measures}

As this study was restricted to cases with skin and joint lesions, we used the ACR core set of outcome measures which are often used in studies in (rheumatoid) arthritis patients. ${ }^{26}$ Outcome measures were: number of swollen and tender joints; duration of morning stiffness; visual analog scale (VAS) for articular pain, physician's global assessment index, patient's global assessment index and ESR. As a multi-item disease activity measure we calculated the SLE Disease Activity Index (SLEDAI). ${ }^{27}$

For the skin we used the disappearances of skin rash as an outcome measure. Skin lesions of any type such as subacute cutaneous lupus erythematosus (SCLE), chronic discoid lupus erythematosus (CDLE), and butterfly rash were scored as present or absent.

Side-effects were recorded at each visit. CBC, serum ALT and creatinine were measured every 2 weeks during the first month and monthly thereafter as followup tests. Ophthalmic evaluation was performed at the end of 6 months.

\section{Statistics}

Data were entered into SPSS 10.1 (SPSS Inc., Chicago, $\mathrm{IL}, \mathrm{US})$. In case of continuous variables, significance of difference between groups was assessed by Student's $t$-test in cases of normally distributed, and MannWhitney $U$-test in non-normally distributed observa- tions. Within-group differences between pre- and posttreatment measures were assessed by Wilcoxon signed rank test. The differences between pre- and post-treatment values of discrete variables were assessed by Fisher's exact test. The final analysis was not done with intention to treat, and only done in the 37 out of 41 who completed the 24 weeks period.

\section{Ethics}

The study was approved by the Ethics Committee of the Bangabandhu Sheikh Mujib Medical University Shahbagh, Dhaka, Bangladesh. The study was performed following the Declaration of Helsinki principles and informed (oral) consent was obtained from all participants before enrolment. As most patients were illiterate, we explained the method orally to the patients and their families and gave extensive possibility for them to ask any questions.

\section{RESULTS}

Forty-one subjects consented to participate in the trial. According to the random order 15 were allocated to the MTX and 26 to the CQ group. Two patients in the MTX group were excluded from therapy, one due to central nervous system involvement, manifested by convulsions, and another due to hepatitis. Two patients in the CQ group discontinued therapy, one due to lack of efficacy and one due to psychosis (the psychosis improved after discontinuation of CQ).

Out of 37 completers, 36 were female. Baseline demographic, clinical and laboratory parameters were nearly identical in the two groups (Table 1). All patients were positive for ANA and at the start of the study all had anti-dsDNA antibodies. After 24 weeks in the CQ group in $8 / 24$ cases dsDNA was still positive and in the MTX group 4/15 still had increased dsDNA. Two patients in the MTX group and four in the CQ group were on a stable dosage of prednisolone, with a maximum of $10 \mathrm{mg}$. As our patients were poor, they could not afford using sunscreen and/or topical steroids.

At baseline the groups did not differ regarding age, sex, illness duration, duration of morning stiffness, joint swelling and pain and VAS pain, patient and physician global assessment (Table 1). The rather high joint tenderness and duration of morning stiffness in both groups may be ascribed to the humid climate, or to sometimes exaggerated estimation by these illiterate patients. 
Table 1 Baseline characteristics of methotrexate and chloroquine groups

\begin{tabular}{|c|c|c|c|}
\hline Characteristics & $\begin{array}{l}\text { Methotrexate }(n=13) \\
\quad(\text { mean } \pm S D)\end{array}$ & $\begin{array}{l}\text { Chloroquine }(n=24) \\
\quad(\text { mean } \pm \text { SD })\end{array}$ & $P$-value \\
\hline Age (years) & $24.0 \pm 4.5$ & $24.9 \pm 7.0$ & 0.299 \\
\hline Sex (female/male) & $13 / 0$ & $23 / 1$ & \\
\hline Duration of illness (months) & $15.4 \pm 12.1$ & $12.2 \pm 9.5$ & 0.216 \\
\hline Number of swollen joint & $7.8 \pm 9.7$ & $2.7 \pm 4.6$ & 0.499 \\
\hline Joint swelling index & $11.7 \pm 19.4$ & $3.4 \pm 5.7$ & 0.475 \\
\hline Number of tender joint & $20.1 \pm 10.0$ & $15.2 \pm 11.2$ & 0.311 \\
\hline Joint tenderness index & $35.7 \pm 21.7$ & $23.0 \pm 17.4$ & 0.233 \\
\hline Morning stiffness (min) & $45.0 \pm 27.0$ & $29.4 \pm 29.0$ & 0.386 \\
\hline VAS for pain & $5.4 \pm 2.3$ & $4.5 \pm 2.6$ & 0.251 \\
\hline Physician's global assessment index & $3.4 \pm 0.7$ & $3.3 \pm 1.0$ & 0.221 \\
\hline Patient's global assessment index & $3.5 \pm 0.7$ & $3.3 \pm 0.8$ & 0.226 \\
\hline Skin rash & 6 & 19 & 0.499 \\
\hline $\operatorname{ESR}(\mathrm{mm} / 1 \mathrm{st} \mathrm{h})$ & $73.5 \pm 38.7$ & $56.9 \pm 30.4$ & 0.455 \\
\hline $\operatorname{ALT}(\mathrm{U} / \mathrm{L})$ & $35.0 \pm 14.0$ & $28.2 \pm 10.8$ & 0.212 \\
\hline Platelet count (per $\mathrm{mm}^{3}$ ) & $240,308 \pm 124,751$ & $288,542 \pm 77,871$ & 0.412 \\
\hline Total white blood cell count $\left(\mathrm{cm}^{3}\right)$ & $7,415 \pm 2,105$ & $7,242 \pm 2,443$ & 0.122 \\
\hline Hemoglobin $(\mathrm{g} / \mathrm{dL})$ & $10.3 \pm 1.6$ & $10.8 \pm 1.5$ & 0.102 \\
\hline
\end{tabular}

ALT, alanine aminotransferase; ESR, erythrocyte sedimentation rate; VAS, visual analog scale.

In the CQ group, all outcome measures improved significantly during the study period. In the MTX group, over 24 weeks, SLEDAI and all clinical and laboratory parameters except ESR improved significantly compared to baseline values (Table 2).

The findings in the outcome measures at the end of the trial did not differ significantly between groups, except morning stiffness $(P<0.05$ in favor of MTX group) and ESR $(P<0.01$ in favor of CQ group) (Table 2). Improvement of skin rash (near disappearance) was significant in both groups but differences between groups were non-significant (Table 3).

\section{Side effects}

Anorexia and nausea were common in both groups. Seven patients in the MTX group and four in the CQ group noticed anorexia and nausea. In most cases anorexia and nausea were mild and all subjects were able to continue the drugs and complete the trial. Rise of serum ALT was observed in two cases in the MTX group. Viral markers were found negative in these

Table 2 Changes in the outcome measures in methotrexate $(n=13)$ and chloroquine $(n=24)$ groups

\begin{tabular}{|c|c|c|c|c|c|c|c|}
\hline \multirow[t]{2}{*}{ Variables } & \multicolumn{3}{|c|}{ Methotrexate group } & \multicolumn{3}{|c|}{ Chloroquine group } & \multirow{2}{*}{$\begin{array}{c}\text { Inter-group } \\
P\end{array}$} \\
\hline & $\begin{array}{c}0 \text { week } \\
(\text { mean } \pm S D)\end{array}$ & $\begin{array}{c}24 \text { weeks } \\
(\text { mean } \pm \text { SD) }\end{array}$ & $P^{*}$ & $\begin{array}{c}0 \text { week } \\
(\text { mean } \pm S D)\end{array}$ & $\begin{array}{c}24 \text { weeks } \\
(\text { mean } \pm \text { SD) }\end{array}$ & $P^{*}$ & \\
\hline Number of swollen joint & $7.77 \pm 9.68$ & $0.77 \pm 1.74$ & $<0.05$ & $2.7 \pm 4.6$ & $1.1 \pm 2.9$ & $<0.05$ & NS \\
\hline Joint swelling index & $11.7 \pm 19.4$ & $1.4 \pm 3.1$ & $<0.05$ & $3.4 \pm 5.7$ & $1.4 \pm 3.4$ & $<0.05$ & NS \\
\hline Number of tender joint & $20.1 \pm 10.0$ & $3.3 \pm 5.3$ & $<0.01$ & $15.2 \pm 11.2$ & $4.1 \pm 6.7$ & $<0.001$ & NS \\
\hline Joint tenderness index & $35.7 \pm 21.7$ & $4.5 \pm 9.1$ & $<0.01$ & $23.0 \pm 17.4$ & $4.8 \pm 9.8$ & $<0.001$ & NS \\
\hline Morning stiffness (minute) & $45.0 \pm 27.0$ & $7.7 \pm 14.8$ & $<0.01$ & $29.4 \pm 29.0$ & $10.4 \pm 22.6$ & $<0.01$ & NS \\
\hline VAS for pain & $5.4 \pm 2.3$ & $1.4 \pm 2.1$ & $<0.01$ & $4.5 \pm 2.6$ & $1.5 \pm 2.2$ & $<0.001$ & NS \\
\hline $\begin{array}{l}\text { Physician global } \\
\text { assessment index }\end{array}$ & $3.4 \pm 0.7$ & $1.5 \pm 1.1$ & $<0.01$ & $3.3 \pm 1.0$ & $1.8 \pm 1.1$ & $<0.001$ & NS \\
\hline Patient assessment index & $3.5 \pm 0.7$ & $1.6 \pm 1.2$ & $<0.01$ & $3.3 \pm 0.8$ & $1.9 \pm 1.1$ & $<0.01$ & NS \\
\hline $\mathrm{ESR}(\mathrm{mm}$ at $1 \mathrm{st} \mathrm{h})$ & $73.5 \pm 38.7$ & $57.3 \pm 29.1$ & NS & $56.9 \pm 30.4$ & $35.0 \pm 21.6$ & $<0.001$ & $<0.01$ \\
\hline SLEDAI & $12.5 \pm 1.2$ & $2.8 \pm 2.4$ & $<0.01$ & $13.3 \pm 0.5$ & $2.5 \pm 2.4$ & $<0.001$ & NS \\
\hline
\end{tabular}

*Wilcoxon signed-rank test. ESR, erythrocyte sedimentation rate; SLEDAI, Systemic Lupus Erythematosus Disease Activity Index; VAS, visual analog scale. 
Table 3 Number of subjects with skin rash before and after treatment

\begin{tabular}{lccccc}
\hline Group & Total & $\begin{array}{c}\text { At } 0 \\
\text { week }\end{array}$ & $\begin{array}{l}\text { At 24 } \\
\text { weeks }\end{array}$ & $P$-value & $\begin{array}{c}\text { Inter-group } \\
P\end{array}$ \\
\hline Methotrexate & 13 & 06 & 0 & $<0.001$ & NS \\
Chloroquine & 24 & 19 & 03 & $<0.001$ & \\
\hline
\end{tabular}

NS, not significant.

Table 4 Adverse effects of methotrexate and chloroquine after 24 weeks

\begin{tabular}{lccc}
\hline Adverse effects & $\begin{array}{c}\text { Methotrexate } \\
(n=13) \\
(\%)\end{array}$ & $\begin{array}{c}\text { Chloroquine } \\
(n=24) \\
(\%)\end{array}$ & $P^{*}$ \\
\hline $\begin{array}{l}\text { Anorexia and } \\
\text { nausea }\end{array}$ & $7(53.8)$ & $4(16.7)$ & $<0.01$ \\
$\begin{array}{l}\text { Raised ALT } \\
\text { Total }\end{array}$ & $2(15.4)$ & 0 & \\
\hline
\end{tabular}

*Fisher's exact test. ALT, alanine aminotransferase.

cases and the liver functions became normal after discontinuation of MTX. The number of adverse events was significantly higher in the MTX group compared to the CQ group (Table 4). The ophthalmic evaluation at the end of 6 months did not reveal any abnormalities in either group of patients. No flares of SLE or end organ damage were observed during the study.

\section{DISCUSSION}

The role of antimalarials in the treatment of cutaneous and articular manifestations of SLE has been well established. ${ }^{3,28-31}$ In some retrospective and uncontrolled studies, MTX has been reported to be effective in controlling steroid-dependent or steroid-resistant articular and cutaneous manifestations of SLE. ${ }^{10-21} \mathrm{~A}$ few of these trials were retrospective. ${ }^{14,22,23}$ Other trials were uncontrolled and included either steroidresistant patients ${ }^{13,15,20,21}$ or patients dependent on high doses of steroid. ${ }^{14,16-18}$

Only two prospective randomized placebo-controlled trials on the efficacy of MTX in SLE have been published, both showing good effect of MTX on controlling cutaneous and articular activity of SLE and corticosteroid dose reduction despite frequent side-effects (gastrointestinal complaints and hepatic enzyme elevations). In both studies higher MTX dosages were used than in ours. A recent trial ${ }^{25}$ was done in a more severe patient group and half the patients had renal and two-thirds cardiovascular, hematologic and other organ involvements. In either arms of the study two-thirds or virtually all (placebo arm) of the patients received HCQ so the results of this study cannot be compared with ours.

None of the studies addressed the issue of safety and efficacy of MTX compared to those of antimalarials. These studies opened our eyes to the use of MTX in articular and cutaneous SLE, but they did not answer the question if MTX could be used as an alternative for antimalarials.

Our prospective, controlled study was the first one designed to compare the efficacy and safety of MTX with CQ in patients with articular and cutaneous lupus not resistant to or dependent on high-dose corticosteroids. As with the previous studies, we demonstrated the efficacy of MTX in controlling articular and mucocutaneous manifestations of SLE. There was a significant improvement in outcome measures in both MTX and CQ groups and the two groups did not significantly differ at the end of the 24-week trial period in most outcome measures. This indicates that MTX is as effective as CQ in articular and mucocutaneous SLE. However, two observations in our limited trial need re-investigation. The fall in ESR was not significant in the MTX group. This may reflect the wellknown fact that ESR does not correlate with disease activity in SLE and is mainly an indication of, for example, infection. Alternatively, antimalarials might be more effective in controlling some aspects of SLE than MTX. The adverse reactions, although not severe enough to warrant withdrawal of the drug, were more frequent in the MTX group. In rheumatoid arthritis, MTX is more potent than antimalarials, but in many cases higher dosages of MTX are needed to get an optimal effect. If we had used a higher dose of MTX, the result might have been that MTX would appear to be more effective than CQ. On the other hand, the patients had a very low weight and the dosage per kg used in our study is comparable with about $20 \mathrm{mg} /$ week in a Western population. In any case, further studies are needed.

We feel that there is a role for MTX in the treatment of patients with articular and mucocutaneous SLE. In daily practice a failure of antimalarial drugs often results in long-term treatment with higher doses of corticosteroids. Our findings and those of others ${ }^{25}$ indicate that MTX can be used as a steroid-sparing agent. Cyclophosphamide and azathioprine are also effective and have steroid-sparing potential, but there is concern about the risks of carcinogenicity or irreversible sterility. ${ }^{32,33}$ To date no evidence of carcinogenicity has 
been reported with MTX. So MTX may be preferable to these agents.

We permitted enrolment of patients on stable dosage of maximum $10 \mathrm{mg}$ prednisolone during the last 2 months before enrolment and no addition or change of dose during the trial period was allowed. Only two patients in the MTX group and four in CQ group were using corticosteroids, so no subgroup analysis was done.

Our study had several limitations and flaws that need to be specifically addressed in designing future studies on efficacy of MTX in SLE. The first limitation is that the study was designed as an equivalence trial, trying to demonstrate that MTX is equivalent to CQ. Although generally no differences were found between the efficacy of MTX and CQ, the small sample size in this study may have masked some true differences between the groups. To confidently conclude that there is absolutely no difference between the two treatments, one would need a very large sample size in order to achieve enough power to identify even small differences on all outcome measures. Therefore, the conclusion that MTX is equivalent to CQ needs to be interpreted with some caution. Although we realize that the sample size in this study was quite small, as it is in most studies on this issue, we had to make do with the available number of SLE cases fulfilling the criteria. SLE is a rare disease $e^{34}$ and studies with larger samples need multi-center collaboration.

Another flaw of our study is that there was no blinding to treatment and this may have biased the outcomes. Owing to lack of financial and logistic support, we could not make a double-blind design. But we do not feel that this has influenced the results, as the majority of the patients were illiterate, so in that way they were more or less blinded. Moreover, this study was done without any funding from industry or government.

We were compelled to use in CQ instead of HCQ, the antimalarial more commonly used in SLE. HCQ is more expensive and not available in Bangladesh and many parts of the world. Moreover, it has been suggested that CQ might be more effective although more toxic than HCQ. ${ }^{35}$ Both HCQ and CQ have comparable immunomodulatory and anti-inflammatory effects and are effective in SLE. ${ }^{3,36}$ Doses used for both MTX and CQ may appear subtherapeutic. Although we considered applying higher or flexible dosages like the treatment schemes applied in rheumatoid arthritis used in Western countries, we decided to choose in this study for low and fixed dosages in these patients with a weight of generally $35-45 \mathrm{~kg}$. Additionally, we did not give folic acid as a supplement, which considering the current literature in RA would have been preferable. Despite this, we observed few side-effects in the MTX-treated patients.

The assessment of the skin lesions was rather crude either presence or absence of skin lesions. We did not allow changes in corticosteroid dosages, so possible changes can be ascribed only to MTX or CQ treatments.

A follow-up period of 6 months, as it was applied in most previous studies with MTX in SLE, does not establish sustained efficacy, so in the future longer follow-up is needed.

\section{CONCLUSIONS}

As a result of our study we conclude that both drugs are useful in SLE patients with skin and articular complaints and as both drugs are cheap and affordable in our country, we advise its use for the benefit of our patients.

Long-term multi-center double-blind collaborative studies, including large samples, will further clarify the relative safety, efficacy and cost-effectiveness of MTX in the treatment of articular and cutaneous lupus as an alternative to the antimalarials.

\section{ACKNOWLEDGMENTS}

We would like to thank all the patients who participated for voluntarily giving up their time to be involved in this study.

\section{CONFLICTS OF INTEREST}

The authors have no conflicts of interest.

\section{REFERENCES}

1 Worrall JG, Snaith ML, Batchelor JR, Isenberg DA (1990) SLE: a rheumatological view. Analysis of the clinical features, serology and immunogenetics of 100 SLE patients during long term follow up. Q J Med 74, 319-30.

2 Wallace DJ (1994) Antimalarial drugs and lupus. Rheum Dis Clin North Am 20, 43-64.

3 Ruiz-Irastorza G, Ramos-Casals M, Brito-Zeron P, Khamashta MA (2010) Clinical efficacy and side effects of antimalarials in systemic lupus erythematosus: a systematic review. Ann Rheum Dis 69, 20-8.

4 Aviña-Zubieta J, Galindo-Rodriguez G, Newman S, et al. (1998) Long-term effectiveness of antimalarial drugs in rheumatic diseases. Ann Rheum Dis 57, 582-7. 
5 Wang C, Fortin PR, Li Y, Panaritis T, Gans M, Esdaile JM (1999) Discontinuation of antimalarial drugs in systemic lupus erythematosus. J Rheumatol 26, 808-15.

6 Donadio JVS, Glassock RJ (1993) Immunosuppressive drug therapy in lupus nephritis: in depth review. Am J Kidney Dis 21(3), 239-50.

7 Kremer JM, Phelps CT (1992) Long-term prospective study of the use of methotrexate in the treatment of rheumatoid arthritis. Update after a mean of 90 months. Arthritis Rheum 35, 138-44.

8 Weinblatt $\mathrm{ME}$, Weissman $\mathrm{BN}$, Holdsworth $\mathrm{DE}$, et al. (1992) Long-term prospective study of methotrexate in the treatment of rheumatoid arthritis. Arthritis Rheum 35, 129-37.

9 Felson DT, Anderson JJ, Meenan RF (1994) The efficacy and toxicity of combination therapy in rheumatoid arthritis. Arthritis Rheum 37, 1487-90.

10 Miescher PA, Riethmüller D (1965) Diagnosis and treatment of systemic lupus erythematosus. Semin Hematol 2, $1-28$.

11 Ferraccioli GF, De Vita S, Bartoli E (1985) Methotrexate benefits in patients with lupus with and without nephritis (Letter). J Rheumatol 22, 1442.

12 Rahman P, Humphrey-Murto S, Gladman DD, Urowitz MB (1988) Efficacy and tolerability of methotrexate in antimalarial resistant lupus arthritis. J Rheumatol 25, 243.

13 Rothenberg RJ, Graziano FM, Grandote JT, et al. (1988) The use of methotrexate in steroid resistant systemic lupus erythematosus. Arthritis Rheum 31, 612-5.

14 Wilke WS, Krall PL, Sheetz RJ, et al. (1991) Methotrexate for systemic lupus erythematosus: a retrospective analysis of 17 unselected cases. Clin Exp Rheumatol 9, 581-7.

15 Guil Garcia M, Garcia Portales R, Fernandez Nebro A, Belmonte Lopez MA, Camps Garcia MT, de Ramon Garrido E (1993) Effectiveness of the treatment of systemic lupus erythematosus with methotrexate. Med Clin (Barc) 101, 361-4.

16 Wilson K, Abeles M (1994) A 2-year, open-ended trial of methotrexate in systemic lupus erythematosus. J Rheumatol 21, 1674-7.

17 Arfi S, Numeric P, Grollier L, Panelatti G, Jean-Baptiste G (1995) Treatment of corticodependent systemic lupus erythematosus with low-dose methotrexate. Rev Med Interne 16, 885-90.

18 Wise CM, Vuyyuru S, Roberts WN (1996) Methotrexate in nonrenal lupus and undifferentiated connective tissue disease, a review of 36 patients. J Rheumatol 23, 1005-10.

19 Kipen Y, Littlejohn GO, Morand EF (1997) Methotrexate use in systemic lupus erythematosus. Lupus 6, 385-9.

20 Gansauge S, Breifbart A, Rinaldi N, et al. (1997) Methotrexate in patients with moderate systemic lupus erythematosus. Ann Rheum Dis 56(6), 382-5.

21 Sato ET (2001) Methotrexate in systemic lupus erythematosus. Lupus 10, 162-4.
22 Sanchez Y, Carvallo A (2004) Methotrexate use in patients with systemic lupus erythematosus. Rev Med Chil 132, 195-201.

23 Wong JM, Esdaile JM (2005) Methotrexate in systemic lupus erythematosus. Lupus 14, 101-5.

24 Carneiro JRM, Sato EI (1999) Double blind, randomized, placebo controlled clincal trial of methotrexate in systemic lupus erythematosus. J Rheumatol 26, 1275-9.

25 Fortin PR, Abrahamowicz M, Ferland D, Lacaille D, Smith CD, Zummer M (2008) Steroid sparing effects of methotrexate in systemic lupus erythematusous: a double-blind randomized placebo controlled trial. Canadian Network for improved outcomes in systemic lupus. Arthritis Rheum 59, 1796-804.

26 Felson DT, Anderson JJ, Boers M, et al. (1993) The American College of Rheumatology preliminary core set of disease activity measures for rheumatoid arthritis clinical trials. Arthritis Rheum 36, 729-40.

27 Bombardier C, Gladman DD, Urowitz MB, Caron D, Chang CH (1992) Derivation of the SLEDAI. A disease activity index for lupus patients. The Committee on Prognosis Studies in SLE. Arthritis Rheum 35, 630-40.

28 Ziff M, Esserman P, Mc Ewen C (1956) Observation on the course and treatment of SLE. Arthritis Rheum 7, 33250.

29 Rothfield N (1988) Efficacy of antimalarials in systemic lupus erythematosus. Am J Med 85(4A), 53-6.

30 Williams HJ, Egger MJ, Singer JZ, et al. (1994) Comparison of hydroxychloroquine and placebo in the treatment of arthropathy of mild systemic lupus erythematosus. J Rheumatol 21, 1437-62.

31 Molad Y, Gorshtein A, Wysenbeek AJ, et al. (2002) Protective effect of hydroxychloroquine in systemic lupus erythematosus; prospective long-term study of an Israeli cohort. Lupus 11, 356-61.

32 McCarthy CJ, Sheldon S, Ross CW, et al. (1994) Cytogenetic abnormalities and hematologic malignancies associated with the use of alkylating agents in rheumatic disease. Arthritis Rheum 37, S428.

33 Rivkees SA, Crawford D (1988) The relationship of gonadal activity and chemotherapyinduced gonadal damage. JAMA 259, 2123-5.

34 Siegel M, Reilly EB, Lee SL, et al. (1964) Epidemiology of systemic lupus erythematosus. Time trend and racial differences. Am J Public Health 54, 33-43.

35 Wallace DJ (2002) Antimalarial therapies. In: Wallace DJ, Bevra HH (eds). Dubois' Lupus Erythematosus, 6th edn, Chapter 55, pp 1149-72. Lippincott Williams \& Willkins, Philadelphia.

36 Canella AC, O’Dell JR (2008) Methotrexate, leflunomide, sulfasalazine, hydroxychloroquine and combination therapies. in: Firestein GS, Budd RC, Harris ED Jr, McInnes IB, Ruddy S, Sergent JS (eds) Kelley's Textbook of Rheumatology, 8th edn, Chapter 56, pp 883-908. Elsevier, Philadelphia. 